in the majority of soils found in rural England. Ordinary earthing - that is, one system earth at the substation and the consumer's earth utilizing the public water mains or the cable sheaths-has proved quite satisfactory in urban areas and has been the general practice in Great Britain. The main difficulty with ordinary earthing occurs when the system is overhead and is situated in a district without a piped water supply. The use of strip electrodes has been the means of reducing substation earth resistances to a reasonable figure and deeply driven rod electrodes have also proved useful.

The chief disadvantage of protective multiple earthing is the danger arising from a broken neutral conductor. To minimize the risk the earth resistance of the neutral is made as low as possible, and earths are provided at all consumers' premises. Where the soil resistivity is high (as would generally be the case) this represents a serious expense. The money might be more advantageously expended in ensuring that in the event of only a neutral breaking it would make contact with a live wire and so blow the fuse and disconnect the supply from the faulty section.

In order to determine the reduction of resistance effected by salting, and the frequency with which it is necessary to re-salt electrodes, tests have been in progress over a period of five years in five different sites where various extremes of soil conditions and rainfall exist. Tables are given showing the seasonal change of resistance of electrolytes and the effect of salt and coke treatment. Whilst salting reduces the resistance of earth electrodes it is generally recognized that it increases the rate of corrosion. The following conclusions are of practical importance. Failure of all electrodes in clay soil is caused by the attainment of a temperature of $100^{\circ} \mathrm{C}$. at the electrode surface. At this temperature the moisture present evaporates, and the resistivity of the soil increases to a very high value. In clay soil with alternating currents, small leakage currents flowing for a long time do not impair the characteristics of an electrode, since they reduce its resistance. On the other hand, they seriously impair an electrode's characteristics if the electrode is connected to a positive lead. New work is now planned on the behaviour of different types of soil, the requirements of Petersen coil earth electrodes, and the behaviour of long electrodes and electrodes in parallel.

\title{
FIRE FIGHTING EQUIPMENT FOR ELECTRICAL INSTALLATION
}

$\mathrm{L}$ AST year the Electricity Commission requested the Electrical Research Association (E.R.A.) to consider what steps should be taken to try to prevent a repetition of one or two disastrous fires that had taken place in connexion with electric power stations and electrical installation. The E.R.A. appointed a committee to consider the whole matter and its report was discussed at the Institution of Electrical Engineers in Iondon on January 25.

Mr. H. W. Swann, H.M. senior electrical inspector for the Home Office, presented the report and opened the discussion. Mr. Swann pointed out that when his committee first took the matter in hand there was a dearth of information available as to the performance of certain media used for fighting fires, and, hearing that a good deal of work had been done in Paris on this subject, the committee paid a visit there and obtained a great deal of information. But it was felt that something more should be done in Great Britain. Luckily, the co-operation was obtained of the County of London Electric Supply Co. at its power station at Barking, and also the help of the London Fire Brigade and the manufacturers of various proprietary media for dealing with fires.

Mr. MeMahon introduced the report of the Com. mittee and showed some colour films illustrating in a striking manner the starting and progress of the experimental fires and how they were extinguished. The length of the films taken amounted to $1 \frac{3}{4}$ miles, about ten per cent of which were shown. The films were very instructive and many lessons were obtained from them. All the fires were artificially created and tests were carried out with methyl bromide gas, carbon dioxide, mechanical foam, chemical foam and water, as extinguishing media.
The recommendation made by the E.R.A. Fire Committee is that, for outdoor oil risks, the most suitable form of fixed installation is the atomized water type, or, if local conditions prevent this, then foam should be used. Failing either of them, inert gas media should be used, although when other media are available gas is not recommended. For indoor oil risks, it is stated that where weatherproof metal-clad gear is installed, atomized water will provide adequate protection, subject to precautions being taken to ensure that any apparatus not of the weatherproof type is not liable to suffer serious water damage. Where there are no draughts, gas protection can be applied, and although protection can be obtained with foam, there is the disadvantage that it leaves deposits which may hinder repair operations. For cables in enclosed spaces not liable to draughts, inert gas protection is effective under conditions of rapid operation. Difficulties may be encountered with water and foam. Much the same remarks are applied to cable galleries exposed to the atmosphere, and where gas is not safely applicable then water or foam installations will afford adequate protection. Certain recommendations are also made with regard to portable apparatus, and it is also recommended that back-up protection by means of water hydrants should be provided in case of emergency.

Mr. Nimmo, one of the Electricity Commissioners, remarked that whilst an examination of the films showed that the risk from oil is obviously so great that some might think that the use of oil-less switch. gear should be enforced, yet it has to be remembered that there is a great deal of oil gear in everyday use, and steps have to be taken to protect it. In his opinion, water properly applied is the best medium; with the other media used in these tests, experts had 
applied them. The ordinary user is still left wondering which is the best to use. Usually it was applied by the station personnel. The cooling effect of water gives it a tremendous advantage over carbon dioxide, methyl bromide or carbon tetrachloride. Accepting this, he suggested that for outdoor and indoor transformers and oil and bitumen-filled switchgear, an automatic atomized water installation might be used, and for cable basements and cellars where oil is not likely to be present, ordinary sprinklers would suffice. Finally, he prefers a water pressure of $60 \mathrm{lb}$. per sq. in and a ten minutes storage supply to the $50 \mathrm{lb}$. and four or five minutes recommended in the report.

Mr. C. M. Kerr, who is an officer of the London Fire Brigade and was also a member of the Fire Committee concerned with these tests, spoke of the difficulty of laying down hard-and-fast rules for dealing with these fires and emphasized the need of ample back-up protection; to this, he thinks, too little attention has been given in the report. He also mentioned the need for attention being given to the maintenance of the various forms of fire fighting equipment as a consideration in determining their choice.

Mr. H. Bright said that although the title of the report was "Fire Fighting Equipment for Electrical Installations", it dealt, as did the discussion, solely with power stations. There are, however, installations, such as those in places of entertainment and elsewhere, where the risk of life from oil fires is very much greater than in power stations. In such cases, certain of the media mentioned must be ruled out because of their toxic or suffocating effects. In such places, too, it would be impossible to drain the oil from the transformers into pits, as was suggested for power stations. The alternative seemed to be to have a large tank.

Mr. Hacking, who replied to the discussion, said that the word 'emulsification' was deliberately not used in the report, because satisfactory results had been obtained using water, when there was no question of emulsification. He agreed that the smoke detector should only be used as a detector.

\title{
INSECT PESTS OF CROPS IN ENGLAND AND WALES
}

\author{
By DR. A. D. IMMS, F.R.S.
}

$\mathrm{B}^{\mathrm{r}}$ ULLETIN No. 118 of the Ministry of Agriculture and Fisheries, recently issued, records the incidence of the more important crop pests for the years 1935-37. The information upon which it is based has been supplied in the main by the advisory entomologists and other reporters. It appears that numerous foreign insects were intercepted by the Ministry's inspectors during their examination of imported plants and others were sent in by the general public. The great majority of these aliens were unlikely to prove either injurious or to establish themselves in Great Britain. A few, however, were of a different category and need brief reference.

The Colorado beetle (Leptinotarsa decemlineata) was represented by a few individuals found in the vicinity of London and Swansea. For the most part they were known to have been introduced through shipping, but no outbreak occurred during the period under review. The chrysanthemum midge (Diarthronomyia sp.) first occurred as an outbreak in 1927 but, by 1930, the pest was reported to have been eradicated. After an interval of six years a new infestation was discovered in southern England and appears to have had origin in plants or cuttings imported from the United States. In order to render the position more secure in future the importation of chrysanthemums has now been prohibited, except under special licence, which prescribes rigorous precautions to be observed.

The asparagus fly (Platyparea pociloptera) had not been previously noted in England until it was discovered by $\mathrm{C}$. Warburton in a garden in Hertfordshire in 1935. Subsequent work carried out by the Ministry's inspectors showed that it is too widely established in that county to render any attempt at eradication practicable. The species is a serious asparagus pest on the Continent of Europe and its presence in England may result in the shortening of the productive life of the beds, but it is probable that reasonable commercial control will be attained.

During the period under review, while many of the regular pests of English crops were prevalent, relatively few are specially noteworthy. Mention, however, must be made of the codling moth, which caused very serious damage in most fruit-growing districts during 1935 although it was much less troublesome in the two succeeding years. On the upland pastures of mid-Wales and parts of northern England, outbreaks of larvæ of the antler moth caused loss of sheep-keep. Wheat and oats were seriously attacked by the aphid Myzus festucae in 1935, large acreages in many districts being almost completely ruined. As with the codling moth, the attacks were much less evident in the other two years.

Among unusual records larvæ of the sword grass moths (Polia vestusta and exoleta) attacking hops and of the holly blue butterfly (Lycoena argiolus) injuring raspberries are of interest.

The bulletin also gives a summary of progress as regards insecticides and their application, and concludes with a useful list of references to papers published in Great Britain, during the triennial period, which are concerned with crop pests and related subjects. Viewed as a whole the situation is very satisfactory. Possible danger from the introduction of the apple maggot from Canada and the United States and of the cherry fruit fly from various European countries has been reduced to small proportions by timely action being taken. Also the well-organized watch kept for the Colorado beetle has amply justified itself, since no outbreak has occurred; yet, on the Continent of Europe, its spread eastwards extends yearly and it now has an almost continuous range from southern France to central Germany. 